\title{
Construction of a Test Bench for bike rim and Brake Rotor
}

\author{
A.K.Matta ${ }^{1}$, V.Purushottam ${ }^{2}$, R.Umamaheswara Rao ${ }^{3}$, Dr.C.L.V.R.R.S.V.Prasad ${ }^{4}$
}

Abstract: - In the paper the development of a test bench which can be used to test the behavior of bike rotor during a braking cycle under dry conditions is described. For the dimensioning of test bench, calculation of theoretical possible brake torque assessment of Disc, heat transfer from a rotating disc, plays an important role.The Development of Brake rotor which can be used to check the hot spots under dry conditions is described.For the test, calculations of theoretical possible Disc torques, measurement of temperature using noncontact temperature measuring device have been done. A special focus is laid on hot spots and temperature distribution in serial tests.The test protocol is checked using graphs.The system gives information that internally ventilated cross-drilled Disc has good structural stability and temperature distribution.

Key words: - Brake Rotor, Heat Transfer,Temperature distribution, Graphs.

\section{Introduction}

To get objective statements about the behavior of brake rotor under defined conditions, there is the need to find another test option besides the outdoor tests, in which only subjective statements from the rider or measured field data under not reproducible conditions can be found. Therefore, a test bench was buit which makes it possible to investigate different brakes under identical conditions in the laboratory. With the developed equipment, a hysteresis function can be logged, that gives information about the relation of the force,caused by the riders hand/fingers, and the measured temperature which effects the brake efficiency. With this information, several statements can be made, e.g. if the brake is acting strong or powerless or if it is easy to handle in critical situations or not. Additional any changing of the brake, like using other brake-pads, special brake discs or changing the brakes piston diameters in the development process can be controlled objectively. The whole test bench, in the final development state, should be able to check any rim temperature.

\section{Measurements and results for the dimensioning}

The key factors to construct a well designed test bench are the knowledge of the appearing mechanical values, such as the temperatures at different spots on Discs keeping brake force constant. To find out these values several measurements took place. To find out the reachable temperatures, two different approaches were chosen. One was to check the maximum reachable value of the temperature with the help of a non contact type infrared thermometer. Its measurement range was set to $-15^{\circ} \mathrm{c}$ to $250^{\circ} \mathrm{c}$ and the other to evaluate theoretically.

\subsection{Heat generated in a Disc rotor $[3]$}
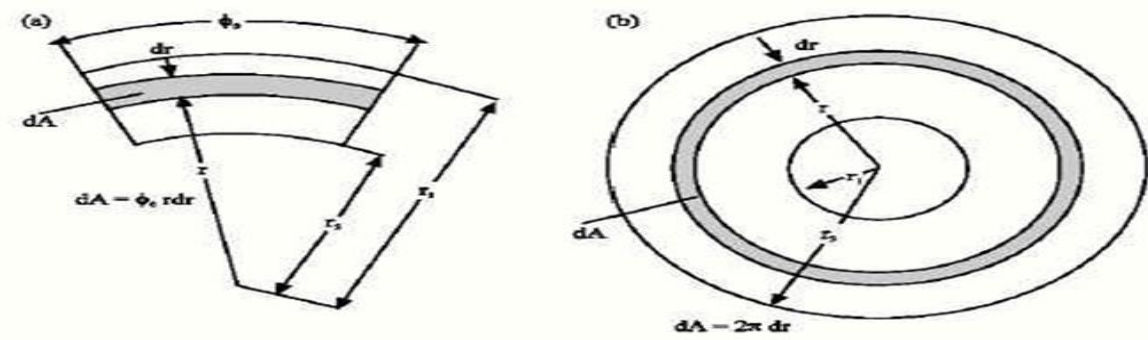

Fig2.1 Contact Surface Area of Pad and Disc

The rates of heat generated due to friction between pad and disc are formulated as follows

$$
\begin{aligned}
& \mathrm{dE}=d \mathrm{P}=\mathrm{VdF}_{\mathrm{f}}=\mathrm{r} \omega \mu \mathrm{p} \phi_{0} \mathrm{rdr} \\
& \mathrm{dE}=\mathrm{dE}_{\mathrm{p}}+\mathrm{dE} \dot{\mathrm{d}}_{\mathrm{d}} \\
& \mathrm{dE}_{\mathrm{p}}=(1-\sigma) \mathrm{dP}=(1-\sigma) \mu \mathrm{p} \omega \phi_{0} \mathrm{r}^{2} \mathrm{dr} \\
& \mathrm{dE} \dot{\mathrm{d}}_{\mathrm{d}}=\sigma \mathrm{dP}=\sigma \mu \mathrm{p} \omega \phi_{0} \mathrm{r}^{2} \mathrm{dr}
\end{aligned}
$$


Where $\mathrm{dE}$ is rate of Heat generated due to friction between two sliding components and $\mathrm{dF}_{\mathrm{F}}$ is the friction coefficient

Heat Flux: To obtain the prescribed heat flux boundary condition at the surfaces of two components of the brake system, rate of thermal energy is divided by the surface contact area of each component.

$$
\begin{aligned}
& \sigma=\frac{\xi_{d} S_{d}}{\xi_{d} S_{d}+\xi_{p} S_{p}} \\
& q_{1}(r, t)=\frac{d E_{p}}{d S_{p}}=(1-\sigma) \mu \operatorname{pr} \omega(t) \\
& q_{2}(r, t)=\frac{d \dot{E}_{d}}{d S_{d}}=\frac{\phi_{0}}{2 \pi} \sigma \mu \operatorname{pr} \omega(t)
\end{aligned}
$$

Heat flux for a uniform pressure distribution is a function of time and space variable $\mathrm{r}$, the angular velocity decreases with time during braking action and work done by friction force grows as radial space variable increases. This phenomenon is quiet often when the pad is new.

Heat transfer coefficient will depend on air flow in the region of brake rotor and vehicle speed.It will therefore vary constantly throughout the braking process .It is generally considered extremely difficult to obtain accurate values of heat transfer coefficient.

\section{$\mathbf{h}=\mathbf{Q} / \mathbf{A}(\mathbf{T})$}

Using the preceding data, the heat transfer coefficients can redily be determined by conducting experiment.

\section{Construction}

With the measured values the test bench could be dimensioned. To get an advantage in comparison to the outdoor tests, the whole test process has to be precise, guarantee constant conditions, requires a small number of test personnel as well as having a fast throughput.

The concept was to use a powerful three-phase motor on whose shaft a hub with the brake disc is mounted. The temperatures are measured with non-contact type infrared thermometer, one for the hand force and one for the resulting brake force.

The engine drives the brake disc with a constant speed. It is powerful enough to keep the adjusted rotation speed of the disc during the whole brake cycle constant.

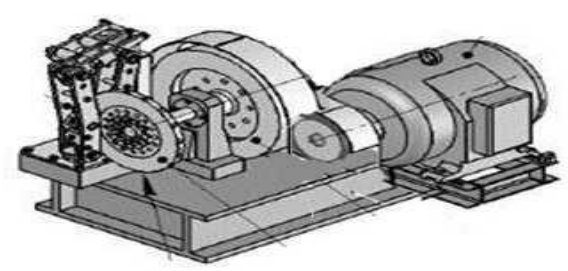

Fig3.1Schematic Representation

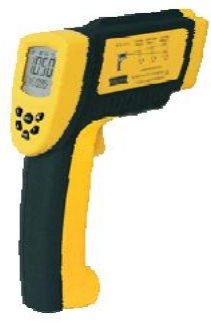

Fig3.2 Non contact type Infrared thermometer

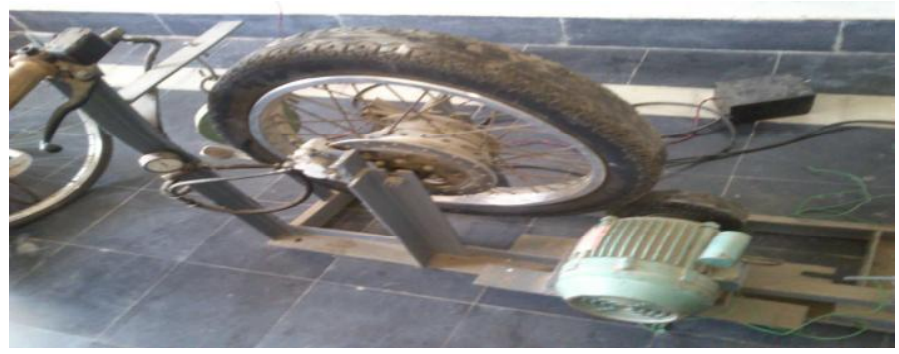

Fig3.3 Experimental Setup 
Spots at which temperatures are measured:

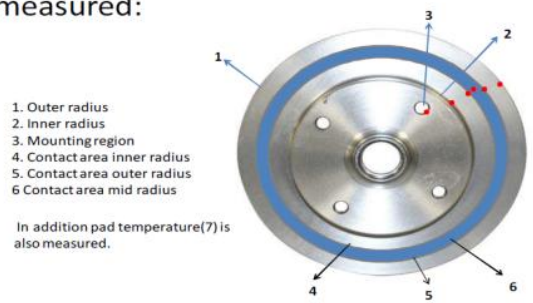

Fig3.4 Areas at which temperatures are measured

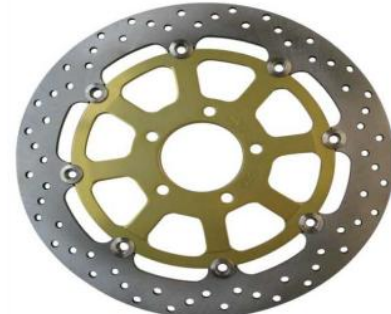

Fig3.5 Cast Iron Disc

For the experiment, a $68633.5 \mathrm{~mm}$ surface area brake rotor was utilized as illustrated in Fig.The rotor was fabricated from cast iron with specific heat of $566\left[\mathrm{Jkg}^{-1} \mathrm{k}^{-1}\right]$. A custom test bench was fabricated to facilitate the rotation of the brake rotor, simulating in vehicle operation. The rotor was driven by a 1 [hp] DC Motor, with speed controller. The resulting setup best simulated the performance of an unobstructed brake rotor open to the atmosphere.

Acquisition of brake rotor tempeatures was accomplished using Infrared thermometer[non-contact] which presents a less intrusive method of temperature acquisition.As such, the measurement error appearing in the results is minimal compared to the assumption of negligible conduction and radiation .This was considered adequate for capturing the spatial temperature distributin of the brake rotor.

An encoder mounted to the rotor shaft facilitates measurement of the rotor speed.The experiment was conducted for the brake rotor.Knowing the convective heat transfer coefficients, experiments were conducted for a nominal speed of 420 [rpm]. And temperature measured at contact surface of disc.

The Disc assembly is the main assembly which allows measuring the temperature. The Disc is measured, using Taly Surf measuring device in which outer radius is $120 \mathrm{~mm}$, inner radius is $80 \mathrm{~mm}$, mounting hole diameter is $7 \mathrm{~mm}$, contact area inner radius is $90 \mathrm{~mm}$, contact area outer radius is $110 \mathrm{~mm}$, crossed drilled hole diameter is $5 \mathrm{~mm}$.

The measured values of the Disc are Surface Area $68633.5 \mathrm{~mm}^{2}$, Speed of the disc measured through tachometer is 420rpm, The brake pressure is measured as 700pa, coefficient of friction 0.42, Pad angle $120 \mathrm{rad}$, Radius $20 \mathrm{~mm}$, Temperature $69.94^{\circ} \mathrm{c}$

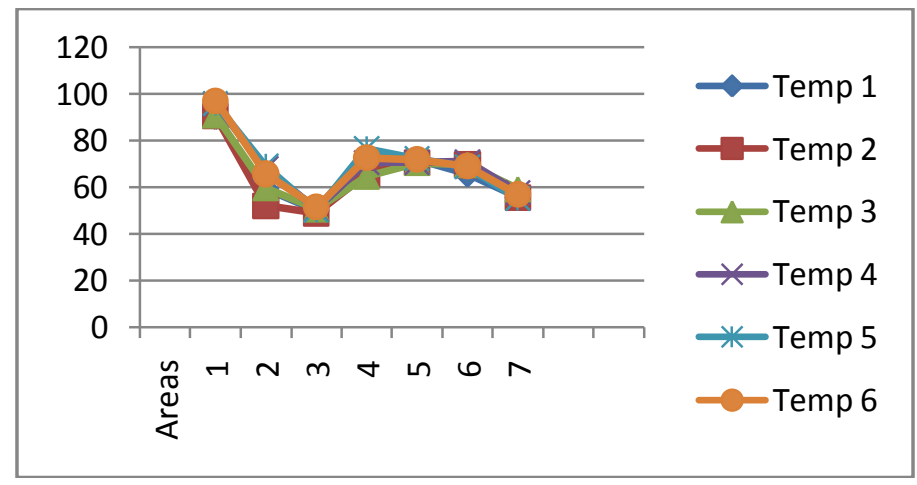

Fig4.1 Effect of experimental temperatures on different Discs.

\section{Discussion and Conclusion}

In conducting the experiments for the brake rotor, it was desired to operate at 420 [rpm].The temperatures at contact surface of rotor and pad are measured with minimum time difference. The major part of experimentation is to find amount of heat generated inside the brake rotor with constant braking pressure and speed.

After evaluating and calibrating, the first test series took place. The results of one disc brake model of the year 2012 are shown. The model was tested with six different types of brake discs, varying in diameter and geometry of the friction ring (Cast Iron Solid Disc,Stainless Steel Solid Disc, Cast Iron Cross Drilled Disc, Stainless Steel Cross drilled Disc, Cast Iron Internally ventilated Disc \& Stainless Steel Internally ventilated Disc). 


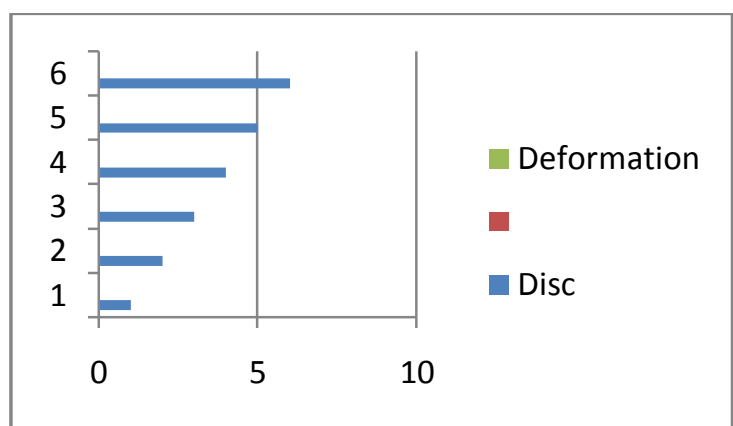

fig 4.2 Effect Deformation on six different Discs

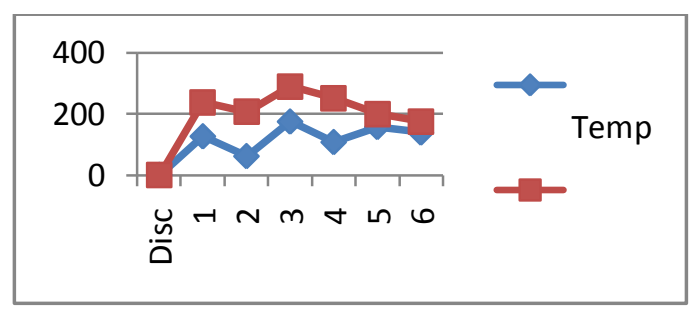

fig 4.4 Temperatures on different Discs

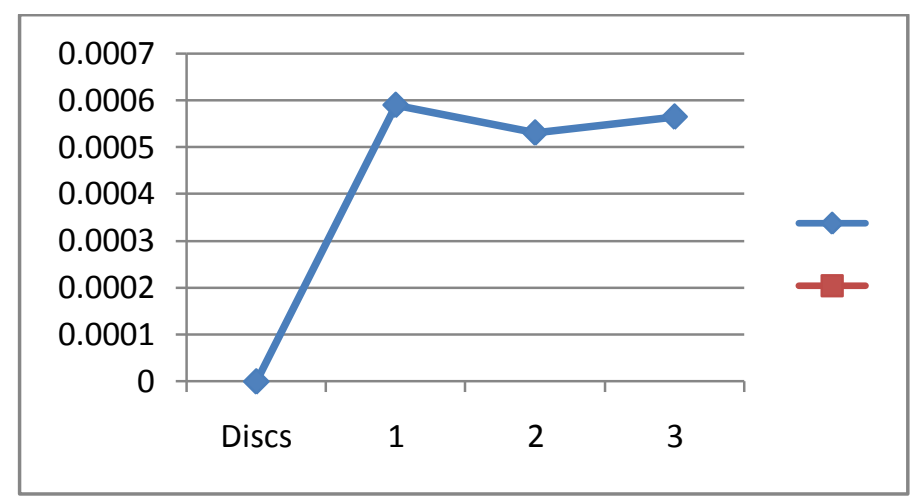

fig4.5 Effect of Deformation on Discs

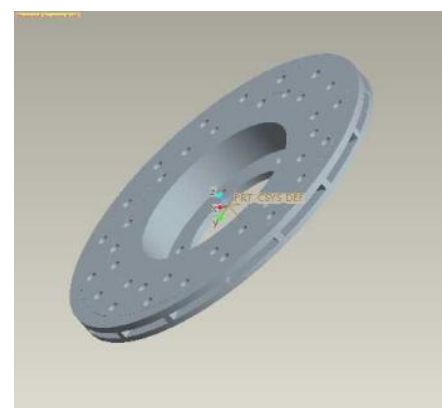

fig4.6 Internally ventilated cross drilled Disc

From the results obtained a new innovative design internally ventilated cross drilled Disc is created using CATIA. And the results are compared with other discs stainless steel cross drilled disc and stainless steel internal ventilated disc. 


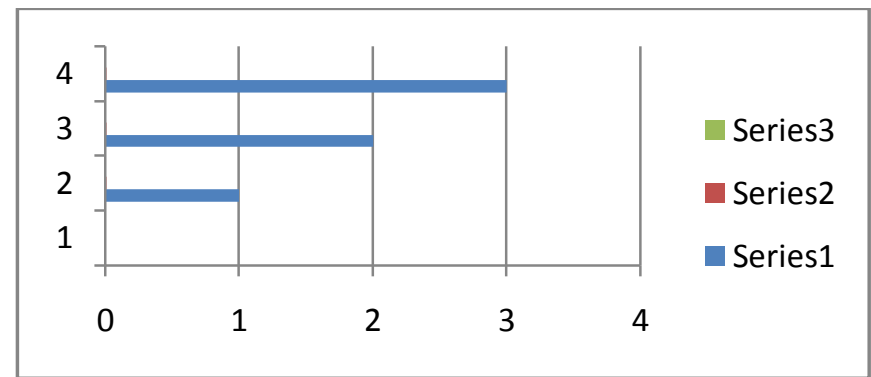

fig 4.7 Effect of Deformation on 3 new discs

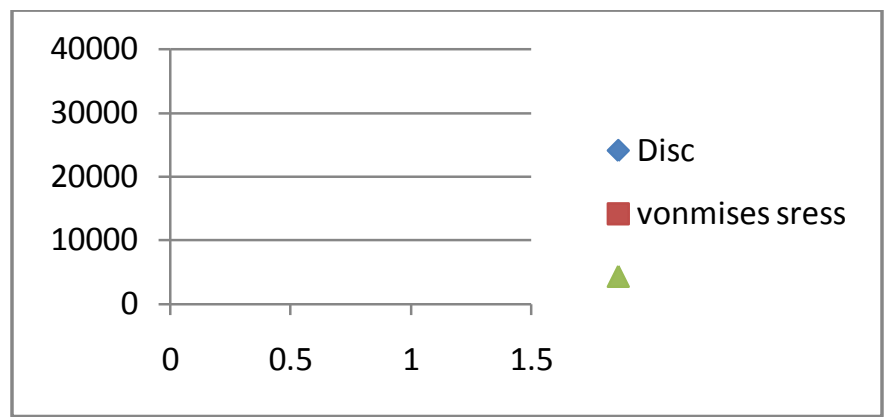

fig 4.8 Effect of vonmises stresses on 3 new Discs

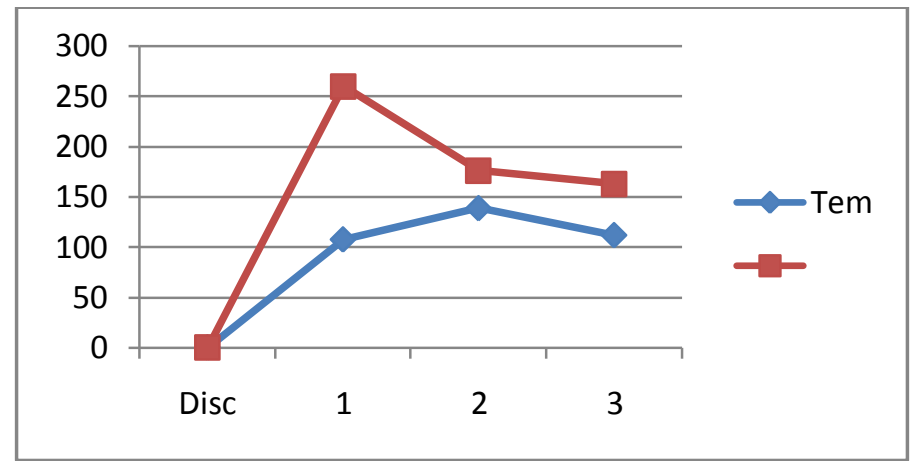

fig 4.9 Effect of temperatures on 3 new Discs

The characteristics of the brake cycles are nearly identical. The reached maximum vonmises stresses, temperatures \& deformations are matching the expected behaviour of the interpreted effects of the different disc designs. The New design internally ventilated cross drilled Disc with material Stainless Steel is expected to perform well inspite of all stringient conditions.

\section{References}

[1] M.Z.Akop, “ Thermal Stress Analysis of Heavy truck brake disc rotor”, ISSN, Vol.1 No.1,pp.2180-1053,2009.

[2] Danet Suryatama, "Thermal Judder on drum brakes due to mounted radial run out ", $2^{\text {nd }}$ ANSA,pp.2180-1053,2009.

[3] F.Talati and S.Jalalifar, "Investigation of Heat Trasfer phenomena in a ventilated disk brake rotor with straight radial rounded vanes",IJAS, 8(20),pp.3583-3592,2008.

[4] A.D.Mcphee, "Experimental heat transfer and flow analysis of a vented brake rotor brake rotor", IJTS,pp.458-467,2008.

[5] S.S.Rao " The Finite Element method in Engineering”, BH Publications, New Delhi, 3rd Edition,pp.166-555,1999.

[6] O.C.Zeinkiewicz "The Finite Element method in Engineering Science", Tata McGraw Hill, 2nd Edition,pp312-515,1992.

[7] Jean-Claude Sabonnadiere and Jean-Louis Coulomb "Finite Element method in CAD”, North Oxford University, 1982.

[8] S. Domkundwar, Dr. C.P.Kothandaramana,A.V. Domkundwar, "Thermal Engineering",SciTech Publications, New Delhi, 3rd Edition, pp 19.1-19.44, 2004.

[9] R.K. Rajput, "Heat and mass Transfer",SciTech Publications, New Delhi, 3rd Edition, pp 435-487, 2009.

[10] Dr. Arkan K. Husain Al-taie, "Stress evalution of low pressure steam turbine rotor Blade and design of reduced stress Blade", vol.26, pg no.169, 2008.

[11]K. Husain Al-taie, "Stress evalution of low pressure steam turbine rotor Blade and design of reduced stress Blade",SciTech Publications, New Delhi, 3rd Edition, pp 435-487, 2009. 